\title{
Desempenho da saccharomyces cerevisiae ao estresse ácido no processo de
}

\section{fermentação alcoólica}

\author{
Performance of saccharomyces cerevisiae to acid stress in the alcoholic fermentation process \\ Desempeño de saccharomyces cerevisiae al estrés ácido en el proceso de fermentación alcohólica
}

Recebido: 26/07/2021 | Revisado: 01/08/2021 | Aceito: 04/08/2021 | Publicado: 09/08/2021

\author{
Bianca Cavalcante Diógenes \\ ORCID: https://orcid.org/0000-0003-3966-152X \\ Universidade Federal Rural do Semi-Árido, Brasil \\ E-mail: biaancacavalcante@gmail.com \\ Shirlene Kelly Santos Carmo \\ ORCID: https://orcid.org/0000-0002-7198-9114 \\ Universidade Federal Rural do Semi-Árido, Brasil \\ E-mail: shirlene@ufersa.edu.br
}

\begin{abstract}
Resumo
As leveduras são fundamentais para um processo fermentativo eficiente na produção de alguns alimentos e bebidas. A eficácia da fermentação depende de vários fatores, dentre eles o $\mathrm{pH}$ do meio. A acidez do mosto e o microrganismo fermentativo estão estreitamente ligados, desse modo, considera-se que o pH ideal para uma fermentação satisfatória, deve estar compreendido entre 4,0 e 5,0. Assim, o trabalho objetivou verificar a atuação da levedura Saccharomyces cerevisiae, quando utilizada na produção de fermentados alcoólicos em meio de estresse ácido. Para isso, as frutas tropicais foram utilizadas como matéria-prima para a fermentação alcoólica, cujo pH do mosto apresentavam-se fora da faixa adequada de operação. Ao fim, os fermentados alcoólicos produzidos foram analisados quanto as suas características físico-químicas e realizada a análise de aceitação através de análise sensorial. Os resultados mostraram que os fermentados produzidos se encontram dentro dos padrões previstos em legislação e possuem boa aceitabilidade a partir da análise sensorial, de onde se pode concluir que, a levedura utilizada apresenta eficácia na sua atividade fermentativa mesmo quando exposta ao estresse ácido.
\end{abstract}

Palavras-chave: Fermentação batelada; Fermentado de frutas; Beneficiamento agroindustrial; Meio ambiente.

\begin{abstract}
Yeasts are essential for an efficient fermentation process in the production of some foods and beverages. Fermentation's effectiveness depends on several factors, including the $\mathrm{pH}$ of the medium. The wort acidity and the fermentative microorganism are closely linked, therefore, it is considered that the ideal $\mathrm{pH}$ for a satisfactory fermentation must be between 4.0 and 5.0. So, the work aimed to verify the performance of the saccharomyces cerevisiae yeast, when used in the production of alcoholic fermented in an acid stress medium. For this, tropical fruit were use as raw material for alcoholic fermentation, whose wort $\mathrm{pH}$ were outside the proper operating range. At end, the alcoholic fermented produced were analyzed for their physicochemical characteristics and the acceptance analysis was carried out through sensory analysis. The results showed that the fermented produced are within the standards foreseen in the legislation and present good acceptability by sensory analysis, from which it can be concluded that the yeast used is effective in its fermentative activity even when exposed to acid stress.
\end{abstract}

Keywords: Batch fermentation; Fermented fruit; Agro-industrial processing; Environment.

\section{Resumen}

Las levaduras son esenciales para un proceso de fermentación eficiente en la producción de algunos alimentos y bebidas. La efectividad de la fermentación depende de varios factores, incluido el $\mathrm{pH}$ del medio. La acidez del mosto y el microorganismo fermentativo están estrechamente vinculados, por lo que se considera que el pH ideal para una fermentación satisfactoria debe estar entre 4.0 y 5.0. Así, el estudio tuvo como objetivo verificar el comportamiento de la levadura saccharomyces cerevisiae, cuando se utiliza en la producción de fermentaciones alcohólicas en un ambiente de estrés ácido. Para ello, se utilizaron frutas tropicales como materia prima para la fermentación alcohólica, cuyo $\mathrm{pH}$ del mosto se encontraba fuera del rango operativo adecuado. Al final, se analizaron las fermentaciones alcohólicas producidas por sus características fisicoquímicas y se realizó el análisis de aceptación mediante análisis sensorial. Los resultados mostraron que los fermentados producidos se encuentran dentro de los estándares previstos en la legislación y tienen una buena aceptabilidad a partir del análisis sensorial, de lo que se puede concluir que la levadura utilizada es eficaz en su actividad fermentativa incluso cuando está expuesta a estrés ácido.

Palabras clave: Fermentación por lotes; Fruta fermentada; Procesamiento agroindustrial; Medio ambiente. 


\section{Introdução}

No ano de 2019, estima-se que 43,1 milhões de toneladas de frutas foram produzidas no Brasil, que ainda ocupa a terceira posição entre os maiores produtores do mundo, atrás da China e da Índia. A maior parte desta produção é absorvida pelo mercado interno, principalmente na comercialização das frutas in natura, e apenas 2,4\% são destinadas à exportação (Embrapa, 2020).

Castro (2012) e Vidal (2018), complementam que a região Nordeste, onde a agricultura familiar é predominante, é responsável por 28,9\% dessa produção. A produção estimada de hortaliças, de acordo com Clemente (2015) é de 19 milhões de toneladas. Enquanto a fruticultura gera 6 milhões de empregos diretos, a olericultura contribui, direta e indiretamente, na criação de cerca de 7 milhões de empregos, com os estados do Rio Grande do Norte e Ceará como destaques na expansão dessa atividade (Abrafrutas, 2018).

Uma das grandes preocupações nos períodos de safras dessas frutas é em relação as perdas ocasionadas. Como afirma Silva (2013), ocorrem durante a pós-colheita e o processamento e atingem $40 \%$ em países em desenvolvimento. Dessa forma, é necessário encontrar alternativas para o aproveitamento desses frutos que perderam seu valor comercial na forma in natura, isso por apresentar, muitas vezes, defeitos nas cascas, tamanhos, coloração, consistência, entre outros (Tessaro, et al., 2010).

Os frutos que não atendem os requisitos mínimos à comercialização muitas vezes acabam sendo doados, repassados para alimentação animal ou até mesmo sendo descartados. Os altos níveis de perdas no período pós safra, levam o pequeno e médio agricultor a prejuízos econômicos, que se traduz diretamente pelos lucros reduzidos em torno do seu produto gerado (Ribeiro, et al., 2014).

Dessa forma, uma das alternativas promissoras à redução destes índices de perdas é a produção de fermentados alcoólicos. Devido à não exigência de um fruto em perfeito estado de qualidade para o uso, isso tem desencadeado diversas pesquisas de tal natureza como forma de aproveitamento destes frutos em sua totalidade, no seu período de safra.

As principais bebidas alcoólicas produzidas no mundo, de acordo com Berenjian (2019) são a cerveja e o vinho, com respectivas 60 e 30 milhões de toneladas sendo produzidas anualmente e com um mercado ainda em crescimento. Segundo a OIV (International Organization of Vine and Wine, que significa “Organização Internacional da Vinha e do Vinho”), o vinho é, exclusivamente, a bebida que resulta da fermentação alcoólica de uvas e do mosto de uvas frescas.

No entanto, outras diversas frutas apresentam boas características sensoriais para a elaboração de vinhos, os quais são conhecidos como "vinhos" alternativos, que tem sido bastante pesquisada e incentivada. Estes "vinhos" alternativos recebem o nome de "fermentado da fruta" ao qual são produzidos, e segundo o Decreto no 2314, de 04 de setembro de 1997 , são as bebidas com graduação alcoólica de 4 a $14 \%$ v/v, a $20^{\circ} \mathrm{C}$, obtidas da fermentação do mosto de fruta sã, fresca e madura (Silva, et al., 2008).

No Brasil, já é possível observar a produção desses fermentados de frutas e acontecem geralmente, numa produção familiar, de forma artesanal e, quase sempre, para consumo próprio, sem visar lucros (Silva Junior, 2019). Cerca de 70\% da produção de álcool é originada pela ação de leveduras, que influenciam diretamente sobre o rendimento, a velocidade do processo fermentativo, assim como, a qualidade do produto obtido (Amorim, 2003).

A Saccharomyces Cerevisiae é uma das principais leveduras utilizadas na biotecnologia em todo o mundo, isso é devido, principalmente, a sua fisiologia única e a papéis-chave que a levedura exerce na fermentação de alimentos e em outros processos industriais (Johnson \& Chavarri-Erasun, 2011).

Segundo Steckelberg (2001) o pH é um dos fatores que afetam o processo fermentativo, sendo importante no controle da contaminação por bactérias, além de afetar o crescimento das leveduras, as taxas de fermentação e a formação de subprodutos. Em meios de baixo pH, por exemplo, ocorre uma redução na produção de glicerol, subproduto importante para o crescimento celular e para a fermentação alcoólica com Saccharomyces Cerevisiae, podendo afetar o crescimento da levedura 
e reduzir a eficácia do processo (Melo, 2006)

Na fermentação em meios ácidos, os ácidos orgânicos podem ser convertidos em outros ácidos, por exemplo, o ácido cítrico pode se transformar em ácido lático e acético (Pinto; Landgraf; Franco, 1996). De acordo com Piper \& Caldeiron (2001) ácidos orgânicos como o ácido acético mencionado anteriormente, quando em meios de baixo pH, se tornam inibidores do crescimento de leveduras, por praticamente não ocorrer dissociação.

No que diz respeito aos benefícios da fermentação em meios ácidos, segundo Lima, Basso e Amorim (2001), essas fermentações obtêm maiores rendimentos de etanol além de reduzir a contaminação bacteriana. Paula, et al., (2012) complementam que "um pH relativamente baixo [...] confere características de frescor à bebida." Ainda assim, se faz necessário que a levedura utilizada consiga resistir ao meio ácido e não comprometer a eficácia do processo de fermentação.

Conforme afirma Dawes (2004), como resposta aos estresses que podem sofrer de acordo com as condições do meio, tais como a temperatura elevada e o pH baixo, as leveduras possuem defesas intrínsecas, dependentes das condições fisiológicas e metabólicas sob as quais foram cultivadas, como a fase de crescimento e o estágio que se encontram em seu ciclo de vida, além de defesas que podem ser induzidas dependendo do tipo de estresse a qual está exposta.

Essa adaptabilidade da Saccharomyces Cerevisiae às alterações do meio, é uma das características que faz esta levedura ser bastante utilizada na indústria, conseguindo ajustar seu metabolismo, resistindo as variações do meio, aos valores de pH baixos, bem como a alta concentração de açúcares e de etanol (Costa, 2017). Dessa forma, esse trabalho teve por objetivo, analisar o desempenho deste tipo de levedura em um meio de estresse ácido de fermentação, assim como, observar a aceitabilidade sobre os produtos obtidos por meio da análise sensorial.

\section{Metodologia}

A produção dos fermentados alcoólicos de frutas com adição de adjuntos ocorreu a partir de um processo artesanal utilizando reator de polipropileno com capacidade de 10 litros na forma de batelada. O processo fermentativo se desenvolveu em um refrigerador com controle de temperatura na faixa de $18^{\circ} \mathrm{C}$. seguindo as instruções obtidas a partir de Garruti, Casimiro e Abreu (2003), por meio de algumas adaptações ao processo, dado que as etapas de sulfitação e ressulfitação não foram realizadas, tendo em vista que os frutos possuíam em suas características próprias, essas condições necessárias a fermentação. As etapas do processo estão indicadas conforme fluxograma (Figura 1).

Para esse trabalho, foi realizada a produção de três fermentados alcoólicos, onde foram utilizados frutos tropicais com características ácidas, sendo estes, a cajarana, o morango e a uva, os quais deram origem a três tipos de fermentados: fermentados de cajarana com adição de morango (Fermentado 1), cajarana com adição de uva (Fermentado 2) e melancia com adição de morango e pimenta rosa (Fermentado 3). 
Figura 1. Fluxograma do Processo.

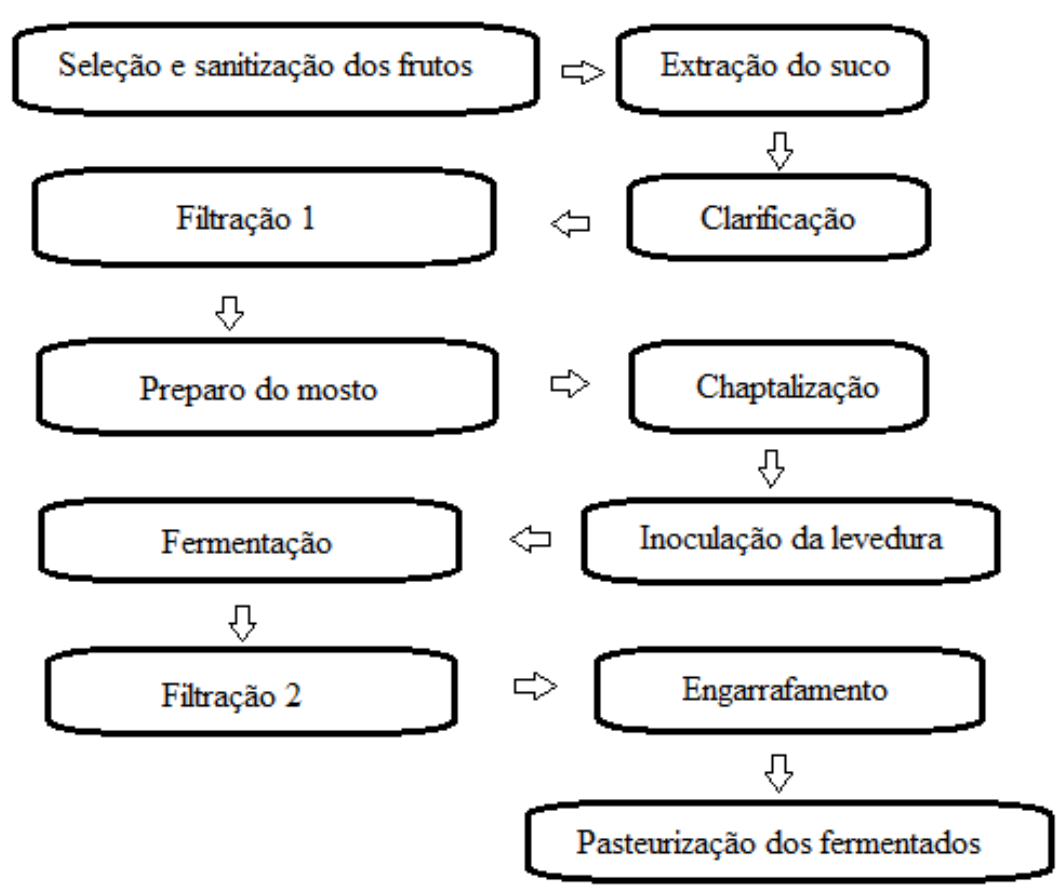

Fonte: Autores.

Os frutos colhidos em propriedades da região, as quais já não apresentavam características satisfatórias e adequadas a comercialização, foram selecionados e sanitizados, onde passaram por uma lavagem durante 30 minutos, com água a $100 \mathrm{ppm}$ de cloro livre e, posteriormente, enxaguados com água corrente para remoção do cloro residual e a partir deles foi produzido o suco natural em uma proporção de 1:3 (polpa da fruta: água). Em seguida, foi realizada a etapa de clarificação do mosto, pela adição de gelatina sem sabor, a $10 \%$ (m/v) em relação ao suco numa proporção de 3g/L, a fim de eliminar substâncias, como a pectina, que podem desencadear a formação do metanol, tornando a bebida imprópria ao consumo, além disso, o uso do clarificante, evita o escurecimento do mosto devido a substâncias suspensas indesejadas.

$\mathrm{Na}$ sequência, o suco correspondente a cada fruta foi filtrado com peneira comum (Filtração 1), para que as fibras grosseiras fossem retiradas, e armazenado em sacos plásticos sob refrigeração. E então realizou-se o processo de caracterização físico-química, em triplicata, baseado na metodologia (Instituto Adolfo Lutz, 2008), analisando o pH e a gravidade específica ( ${ }^{\circ}$ Brix), por meio de um refratômetro. Esse processo é fundamental para determinar a quantidade de açúcar necessária para a correção do mosto de forma a estabelecer condições para que o fermentado produzido esteja dentro do padrão previsto em legislação.

$\mathrm{Na}$ etapa de chaptalização, o mosto é corrigido pela adição de uma determinada quantidade de sacarose, que neste caso foi o açúcar cristal, e esse quantidade foi calculada a partir da leitura inicial do ${ }^{\circ}$ Brix do mosto. Isso se faz necessário para que o fermentado produzido atinja um teor alcoólico dentro dos padrões estabelecidos por lei que caracteriza esse tipo de bebida alcoólica. Na preparação do mosto foram estabelecidas as proporções fruta/adjunto, conforme apresentado na Tabela 1.

Tabela 1. Composição de frutas em cada fermentado

\begin{tabular}{cccccc}
\hline Fruto & $\begin{array}{c}\text { Cajarana } \\
(\%)\end{array}$ & $\begin{array}{c}\text { Morango } \\
(\%)\end{array}$ & $\begin{array}{c}\text { Uva } \\
(\%)\end{array}$ & $\begin{array}{c}\text { Melancia } \\
(\%)\end{array}$ & $\begin{array}{c}\text { Pimenta } \\
\text { Rosa (\%) }\end{array}$ \\
\hline Fermentado 1 & 80 & 20 & -- & -- & --- \\
Fermentado 2 & 50 & --- & 50 & --- & -- \\
Fermentado 3 & --- & 29 & --- & 70 & 1 \\
\hline
\end{tabular}

Fonte: Autores. 
Em geral, para ambientes fermentativos nos quais as condições são inadequadas para o desenvolvimento e reprodução das leveduras, como é o caso do baixo valor do pH, indica-se a correção do meio utilizando a adição de bases como o Hidróxido de Sódio $(\mathrm{NaOH})$, porém, a fim de analisar, justamente, a influência desse parâmetro nesse processo fermentativo, as condições originais existentes foram mantidas.

Após a chaptalização, a levedura Saccharomyces Cerevisiae foi ativada em ambiente a parte como forma de preparação da sua estrutura celular para o meio fermentativo, assim como, para multiplicação inicial de células, e então inoculada ao mosto para iniciar o processo de fermentação. Manteve-se a temperatura controlada em $18{ }^{\circ} \mathrm{C}$ e a cada $24 \mathrm{~h}$ de fermentação foi analisado o ${ }^{\circ}$ Brix como forma de analisar o término da fermentação, através da estabilização da atividade da levedura. Na sequência foi realizada uma nova filtração (Filtração 2) por meio de um sistema de filtração a vácuo (Figura 2), de maneira que fosse possível obter o fermentado limpo e livre de partículas suspensas originadas no próprio processo.

Figura 2. Sistema de filtração a vácuo.

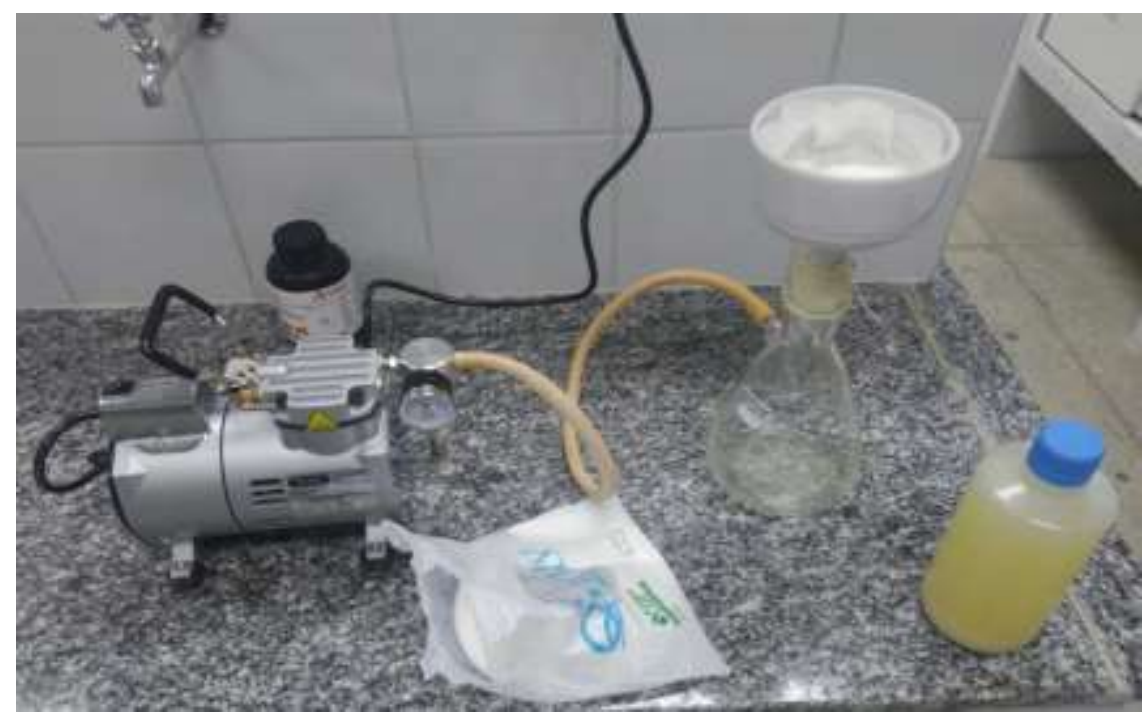

Fonte: Autores.

Por fim, os fermentados foram engarrafados em garrafas de vidro próprias para armazenamento de vinhos, previamente limpas e sanitizadas. Posteriormente, submeteu-se ao processo de pasteurização, que consistiu em um "choque térmico" aplicado na garrafa, no qual as garrafas foram aquecidas em banho-maria, a $65^{\circ} \mathrm{C}$ durante 30 minutos e posteriormente, realizado com o resfriamento das garrafas em um recipiente contendo água fria. Esse procedimento tem como objetivo, matar quaisquer resquícios de microrganismos indesejáveis originados na fermentação.

Os fermentados foram submetidos a uma análise sensorial, de acordo com a escala hedônica, seguindo a metodologia de Instituto Adolfo Lutz, (2008) e realizada por 15 avaliadores, onde parte destes possuíam perfil leigo e outra parte com perfil enófilo, cujos são apreciadores de bebidas alcoólicas fermentadas. Os mesmos avaliaram características dos produtos quanto a sua aparência, aroma e sabor.

\section{Resultados e Discussão}

Com base na avaliação quanto as características físico-químicas dos frutos in natura estudado (Tabela 2), pode-se confirmar o caráter ácido em todos eles, reforçando o interesse pelo estudo sobre a atividade da levedura Saccharomyces Cerevisiae sobre fermentação em ambientes de stress ácido. 
Tabela 2. Valores de $\mathrm{pH}$ e ${ }^{\circ}$ Brix iniciais para os frutos.

\begin{tabular}{ccccc}
\hline Fruto & Cajarana & Morango & Uva & Melancia \\
\hline $\mathrm{pH}$ & $2,25 \pm 0,01$ & $2,75 \pm 0,03$ & $2,8 \pm 0,01$ & $3,3 \pm 0,01$ \\
${ }^{\circ}$ Brix & $11,0 \pm 0,05$ & $3,0 \pm 0,02$ & $15,0 \pm 0,1$ & $10,5 \pm 0,01$ \\
\hline \multicolumn{5}{c}{ Fonte: Autores. }
\end{tabular}

Assim como para os frutos in natura, os mostos e os fermentados produzidos também foram avaliados quanto as suas características em relação ao pH e ao ${ }^{\circ}$ Brix conforme apresentado na Tabela 3.

Tabela 3. Valores de $\mathrm{pH}$ e ${ }^{\circ}$ Brix iniciais para os mostos e fermentados alcoólicos.

\begin{tabular}{cccc}
\hline Fermentado & Fermentado1 & Fermentado 2 & Fermentado 3 \\
\hline pH inicial & $2,0 \pm 0,01$ & $2,3 \pm 0,01$ & $3,8 \pm 0,02$ \\
pH final & $1,8 \pm 0,01$ & $2,1 \pm 0,01$ & $3,5 \pm 0,04$ \\
${ }^{\circ}$ Brix inicial (mosto) & $15,8 \pm 0,03$ & $16,0 \pm 0,05$ & $19,0 \pm 0,02$ \\
${ }^{\circ}$ Brix final (fermentado) & $4,6 \pm 0,01$ & $8,7 \pm 0,01$ & $5,9 \pm 0,01$ \\
\hline
\end{tabular}

Fonte: Autores.

Como pôde ser observado, os valores de $\mathrm{pH}$, tanto inicialmente, quanto no término, se mantiveram abaixo dos valores indicados como adequados para uma boa fermentação. Com isso, ao verificar os valores do ${ }^{\circ}$ Brix, denota-se que a levedura conseguiu desempenhar o seu papel, mesmo em ambiente de alta acidez, na conversão de açúcares, os que consequentemente, dão origem ao álcool. Liu, et al. (2015) esclarecem que o baixo pH inicial facilita o crescimento das leveduras, porém, valores de pH menores que 2,5 podem inibir esse crescimento, resultando em uma taxa de fermentação menor, além de maior teor final de ácido acético e glicerol.

Com os dados de ${ }^{\circ}$ Brix inicial e final, foram calculados os teores alcoólicos para cada fermentado, como apresentado na Tabela 4, onde se mantiveram dentro dos valores previstos em legislação para esse tipo de produto. Como resultado final, os fermentados produzidos, Fermentado 1 (Figura 3.A); Fermentado 2 (Figura 3.B) e Fermentado 3 (Figura 3.C) obtiveram, respectivamente, teores alcoólicos (\%ABV), 9,6\%; 6,7\% e 11,50\%.

Figura 3. Fermentados Alcoólicos.

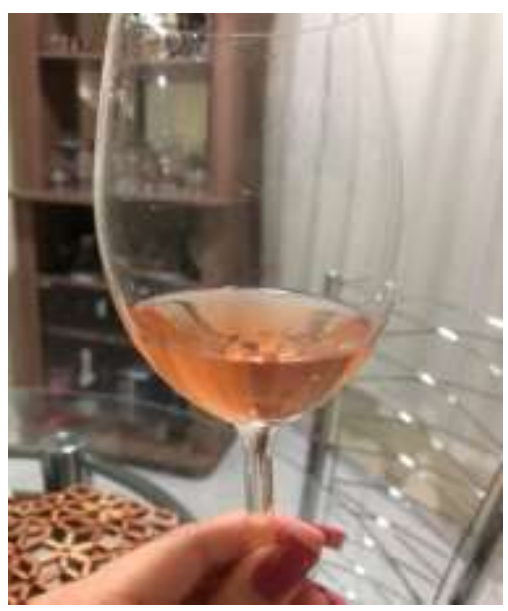

(3.A)

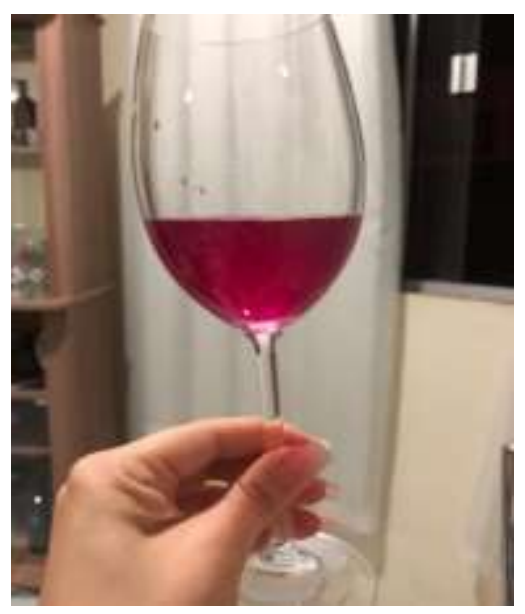

(3.B) 


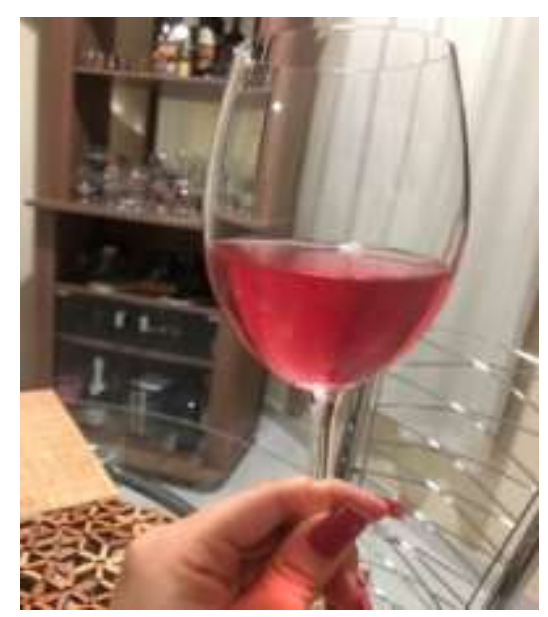

(3.C)

Fonte: Autores.

Após a análise sensorial, de acordo com a avaliações dos degustadores, observou-se que o Fermentado 1 apresentou um aroma destacado do morango superior a presença da cajarana, quanto no sabor, avaliado como adocicado e muito bom, a cajarana é a única fruta perceptível. Para o Fermentado 2, as frutas não foram identificadas pelo aroma nem pelo sabor, ainda assim, o sabor foi considerado como muito bom. Por fim, o Fermentado 3, percebe-se a presença da melancia bem pronunciada ao aroma, no sabor, a pimenta rosa é bastante perceptível, assim como o morango. A aparência deste último foi considerada turva, e a dos outros dois, translúcida.

É possível ainda observar que o Fermentado 3 foi o que apresentou o teor alcoólico final mais elevado, fato este que denota mais uma vez, o ambiente mais adequado ao desenvolvimento do microrganismo Saccharomyces Cerevisiae, visto que, o pH do meio apresentava um pH inicial de 3,8, próximo ao 4,0 indicado na faixa ótima de operação para fermentação.

\section{Considerações Finais}

Os resultados obtidos na produção dos fermentados foram positivos, demonstrando a obtenção de fermentados alcoólicos dentro dos padrões e com boa aceitabilidade, dessa forma, podendo verificar que a levedura Saccharomyces Cerevisiae se apresenta como um microrganismo eficaz mesmo em condições de estresse ácido no processo fermentativo. O meio ácido apresenta ainda outras vantagens, pois torna o meio menos sujeito a contaminação bacteriana, resultando em um maior rendimento alcoólico. Além disso, pode-se observar através desses estudo, propostas de fermentados alcoólicos, a partir da junção de frutos e adjuntos, o que traz novas oportunidades de produto ao mercado, assim como, proporciona uma alternativa a destinação de frutos que, em grande parte dos seus períodos de safra, acabam sendo descartados por estarem machucados e não apresentarem uma qualidade adequada para os padrões de comercialização, o que vem a possibilitar uma fonte extra de renda ao agricultor familiar.

\section{Agradecimentos}

Ao $\mathrm{CNPq}$ pelo incentivo a pesquisa e extensão e financiamento de bolsas para a continuação de projetos. E a Universidade Federal Rural do Semiárido, por meio do Grupo de Pesquisa em Processos e Análises Químicas (GPAQ) pela disponibilidade de laboratórios e incentivo a educação. 


\section{Referências}

Abrafrutas (Associação Brasileira dos Produtores Exportadores de Frutas e Derivados) (2018). Cenário Hortifruti Brasil https://abrafrutas.org/wpcontent/uploads/2019/09/relatorio-hortifruti.pdf.

Amorim, H. V., \& Lopes, M. L. Ciência e tecnologia na seleção de leveduras para produção de etanol (2013). Anais do Simpósio Microrganismos em Agroenergia: da Prospecção aos Bioprocessos. Brasília: Embrapa Agroenergia, 42-59. https://www.embrapa.br/busca-de-publicacoes//publicacao/976228/da-prospeccao-aos-bioprocessos-anais.

Berenjian, A. (2019). Essentials in Fermentation Technology. Switzerland: Springer Nature, Switzerland AG, p. 34.

Castro, C. N. de. (2012). A agricultura no Nordeste brasileiro: oportunidades e limitações ao desenvolvimento. Texto para Discussão, no 1786 (Ed). https://www.ipea.gov.br/portal/index.php?option=com_content\&view=article\&id=16111.

Clemente, F. M. V. T. (2015). Produção de hortaliças para agricultura familiar. Embrapa, (Ed. Téc.). https://www.embrapa.br/busca-de-publicacoes//publicacao/1020866/producao-de-hortalicas-para-agricultura-familiar.

Costa, A. C. T. (2017). Resposta a estresses consecutivos em Saccharomyces cerevisiae. 56 f. Dissertação (Mestrado em Biotecnologia) - Universidade Federal do Espírito Santo (UFES).

Dawes, I. W. (2004). Stress responses. The metabolism and molecular physiology of Saccharomyces cerevisiae. CRC Press LLC, $376-438$.

Embrapa (2020). Embrapa em números. Embrapa, Secretaria Geral, Gerência de Comunicação e Informação. Acesso em 05 nov, 2020 de https://www.embrapa.br/embrapa-em-numeros.

Garruti, D. S, Casimiro, A. R. S., \& Abreu, F. A. P. (2003). Processo agroindustrial: elaboração de fermentado de caju. (Embrapa Agroindustria Tropical). Comunicado Tecnico, 82). 6p. Fortaleza. https://www.embrapa.br/busca-de-publicacoes/-/publicacao/425898/processo-agroindustrial-elaboracao-defermentado-de-caju.

Instituto Adolfo Lutz (São Paulo). Métodos físico-químicos para análise de alimentos. São Paulo: Instituto Adolfo Lutz, 2008.

Johnson, E. \& Echavarri-Erasun, C. (2011). Yeast Biotechnology. 21-44. 10.1016/B978-0-444-52149-1.00003-3.

Lima, U. A., Basso, L. C., \& Amorim, H. V (2001). Produção de Etanol. In: Lima, U. A., Aquarone, E., Borzani, W., Schmidell, W. Biotecnologia Industrial Processos Fermentativos e Enzimáticos. Editora Edgard Blucher (p. 1-43).

Liu, X., Jia, B, Sun, X., Ai, J., Wang, L., Wang, C., Zhao, F., Zhan, J., \& Huang, W (2015). Effect of initial ph on growth characteristics and fermentation properties of saccharomyces cerevisiae. Journal of Food Science. 10.1111/1750-3841.12813.

Melo, H. F (2006). Resposta ao estresse ácido em leveduras da fermentação alcoólica industrial. Tese (Doutorado em Biologia dos fungos). Universidade Federal de Pernambuco, Recife - PE. https://repositorio.ufpe.br/handle/123456789/650.

Paula, B., Carvalho Filho, C. D., Matta, V. M., Menezes, J. da S., Lima, P. da C., Pinto, C. O., \& Conceição, L. E. M. G (2012). Produção e caracterização físico-química de fermentado de umbu. Ciência Rural. 10.1590/S0103-84782012000900027

Pinto, U. M., Landgraf, M., \& Franco, B. D. G. de M. (2019). Deterioração microbiana dos alimentos. In: Microbiologia e higiene de alimentos: teoria e prática. Rubio.

Piper, P., Caldeiron, C. O., Hatzixanthis, K., \& Mollapour, M (2001). Weak acid daptation: The stress response that confers yeast with resistance to organic acid food preservatives. Microbiology (p. 2635-2642). 10.1099/00221287-147-10-2635.

Ribeiro, T. P., Lima, M. A. C. de, Souza, S. O. de, \& Araújo, J. L. P. A. (2014). Perdas pós-colheita em uva de mesa registradas em casas de embalagem e em mercado distribuidor. Revista Caatinga, 25, 67-74. https://periodicos.ufersa.edu.br/index.php/caatinga/article/view/2682/pdf_87.

Silva, P. H. A. et al (2008). Avaliação da composição química de fermentados alcoólicos de jabuticaba (myrciaria jabuticaba). Química Nova [online]. 31, 595-600. 10.1590/S0100-40422008000300025

Silva, J. (2013). Embrapa discute redução de perdas de alimentos. Embrapa. https://www.embrapa.br/busca-de-noticias/-/noticia/1497766/embrapa-discutereducao-de-perdas-de-alimentos.

Silva Junior, C. M. F. (2019). Produção e análise sensorial de vinhos artesanais produzidos com frutas cítricas do semiárido. TCC (Bacharel em Ciência e Tecnologia). Universidade Federal Rural do Semi-Árido. http://repositorio.ufersa.edu.br/handle/prefix/4275.

Steckelberg, C. (2001). Caracterização de leveduras de processos de fermentação alcoólica utilizando atributos de composição celular e características cinéticas. Tese (Doutorado em Engenharia Química). Universidade Estadual de Campinas, Faculdade de Engenharia Química, http://repositorio.unicamp.br/jspui/handle/REPOSIP/267641.

Tessaro, D., Larsen, A. C., Dallago, R. C., Damasceno, S. G., Sene, L., Coelho, S. R. M. (2010). Avaliação das fermentações alcoólica e acética para produção de vinagre a partir de suco de laranja. Acta Scientiarum. Technology. 32. 201-205. 10.4025/actascitechnol.v32i2.4275.

Vidal, M. de F (2018). Comportamento recente da fruticultura na área de atuação do BNB. Caderno Setorial Etene, Ano 3. https://www.bnb.gov.br/documents/80223/3686680/35_Fruticultura_2018.1.pdf/b5660ef3-4ea7-7f44-090f-09b5a3c49097. 